\title{
eCommons@AKU
}

Department of Paediatrics and Child Health

Division of Woman and Child Health

May 2017

\section{Quality of life perceptions in school-going adolescents with social anxiety}

Syeda Ayesha Farooq

Aga Khan University, ayeshafarooq24@gmail.com

Aeman Muneeb

Aga Khan University

Warda Ajmal

Aga Khan University

Maaida Asif Tauni

Aga Khan University

Sana Mahmood

Aga Khan University

See next page for additional authors

Follow this and additional works at: http://ecommons.aku.edu/

pakistan_fhs_mc_women_childhealth_paediatr

Part of the Pediatrics Commons

\section{Recommended Citation}

Farooq, S. A., Muneeb, A., Ajmal, W., Tauni, M. A., Mahmood, S., Qadri, S. S., Butt, A. Y., Mustafa, S. F., Sohai, S. H., Rizvi, N. (2017). Quality of life perceptions in school-going adolescents with social anxiety. Journal of Childhood \& Developmental Disorders, 3(2).

Available at: http://ecommons.aku.edu/pakistan_fhs_mc_women_childhealth_paediatr/232 


\section{Authors}

Syeda Ayesha Farooq, Aeman Muneeb, Warda Ajmal, Maaida Asif Tauni, Sana Mahmood, Syed Kalimullah Sohaib Qadri, Asfand Yar Butt, Syed Farrukh Mustafa, Syed Hamza Sohai, and Narjis Rizvi 


\section{Quality of Life Perceptions in School-Going Adolescents with Social Anxiety}

\section{Abstract}

Introduction: Social anxiety is common among adolescents with a prevalence range of $9-34 \%$. People with social anxiety have intense fear of being evaluated negatively when they come in contact with strangers and as a result they are less satisfied with their life experiences. Our study aimed to screen school going adolescents for social anxiety disorder and to estimate their perceptions about quality of life.

Methods: This cross-sectional study was conducted in Karachi, Pakistan from January to February 2016. We recruited 450 high-school students of ages 14-17 using a self-administered questionnaire based on the Liebowitz Social Anxiety Scale for Children and Adolescents (LSAS-CA-SR) and the brief version of the World Health Organization Quality of Life (WHOQOL-BREF) questionnaire.

Results: In this school-based study, $23.8 \%$ screened positive for social anxiety with a preponderance of adolescents from public than private schools ( $33 \%$ vs. $18 \%$, $\mathrm{p}<0.001)$. Social anxiety status, however, was not associated with gender and age. Screening positive for social anxiety was found to be associated with a significant difference in mean scores on all four domains (physical health, psychological health, social relationships, and environment) of WHOQOL-BREF.

Conclusion: Social anxiety is prevalent among Pakistani school adolescents with a substantial negative effect on quality of life. Adolescents must be targeted with interventions such as group treatment and mentorship programs that are effective in tackling the menace of social anxiety.

Keywords: Social anxiety; Adolescents; Quality of life

Abbreviations: LSAS-CA-SR: Self-report version of the Liebowitz Social Anxiety Scale for Children and Adolescents; WHOQOL-BREF: The brief (26-question) version of the original 100-question World Health Organization Quality of Life Questionnaire

\author{
Syeda Ayesha Farooq, \\ Aeman Muneeb, \\ Warda Ajmal, \\ Maaida Asif Tauni, \\ Sana Mahmood, \\ Syed Kalimullah Sohaib \\ Qadri, \\ Asfand Yar Butt, \\ Syed Farrukh Mustafa, \\ Syed Hamza Sohail and \\ Narjis Rizvi
}

Aga Khan University, Karachi, Pakistan

Corresponding author:

Syeda Ayesha Farooq

झ ayeshafarooq24@gmail.com

Medical College, Aga Khan University, Stadium Road, Karachi 74800, Pakistan.

Tel: 00923343203201

Citation: Farooq SA, Muneeb A, Ajmal W, et al. Quality of Life Perceptions in School-Going Adolescents with Social Anxiety. J Child Dev Disord. 2017, 3:2.

Received: April 10, 2017; Accepted: May 28, 2017; Published: May 02, 2017

\section{Introduction}

Social anxiety is common in adolescence [1]. It is defined as the excessive fear of embarrassing oneself when placed in a social or performance situation where one is likely to be scrutinized and judged by strangers [2]. Kessler et al. predicted a $13 \%$ lifetime prevalence of social anxiety disorder in the United States, making it the third most prevalent mental disorder after depression and alcohol abuse $[3,4]$. Adolescents make up 1.2 billion of the world population [5]. Prevalence of social anxiety disorder among adolescents has been reported as $9 \%, 10 \%$, and $34 \%$ for United States, India, and Saudi Arabia respectively [6-8].
The multifactorial etiology of social anxiety has been the subject of many studies. As with other mental illnesses, environmental, genetic and behavioral factors contribute to its pathogenesis [9].

Pakistan is a low-middle income country and has battled many challenges including terrorism that have led to high rates of mental illness among its citizens. As of 2014, it has a population of 192 million. Forty millions of Pakistan's population consists of adolescents (11-19-year-olds) [10]. Social anxiety has a substantial negative effect on the quality of life-the subjective sense of life satisfaction and well-being of a person. The adolescents afflicted, 
tend to be under-confident and report functional deterioration; eventually leading to a decline in their academic performance and peer interactions [11]. In spite of this, few seek help. In a clinic setting, Katzelnick et al. diagnosed social anxiety disorder in $8.2 \%$ of 7165 participants; only $0.5 \%$ of these had a pre-existing diagnosis of the same [12].

Mental health, in general, and child psychiatry in particular, have been neglected in Pakistan. There are currently no countrywide studies that estimate the burden of mental illness among children [13]. According to the World Health Organization, in 2008, there were only 342 psychiatrists in the country and a mere $0.4 \%$ of the allocated health budget was spent on mental health [14]. In these dire circumstances, it has become imperative to determine the undiagnosed burden of social anxiety as it can coexist with mental illnesses such as major depression, generalized anxiety disorder and substance use disorder [4]. Identification of these high-risk individuals can help implement targeted mental health interventions before functional impairment sets in, making the situation challenging to treat and control.

Our paper presents results on the prevalence of social anxiety among adolescents and their perceptions about quality of life.

\section{Methods}

This cross-sectional study was conducted among school going children of selected schools in Karachi, Pakistan from January to February 2016. Students between the ages of 14-17 were invited to participate in the study, as this is the age when social anxiety generally manifests $[7,15]$.

The Aga Khan University Ethics Review Committee approved the study protocol and questionnaire. Before embarking on the main study, we pre-tested the questionnaire on 10 students of ages 14-17 from a public/private school, which was not included in the main sample. Using the results from the pre-test survey, we modified the questionnaire to the cultural context of Pakistan. The modifications in the questionnaire are available on request.

We approached 9 schools in Karachi, based on the social class that they belong to, asking for permission to conduct the survey. Four schools gave permission, of these, two were subsidized government-run public schools and two were private schools that cater to the higher socio-economic group. Informed consent was taken from the principals of all four schools.

We approached all students who were present in school on the scheduled day of our visit. All students of ages 14-17, who gave consent, were enrolled. First, the students were given a brief talk regarding the questionnaire. They were then asked to fill out the form and all queries were addressed by the authors. Questionnaires were collected at the end and reviewed. All participants who had missed any questions were asked to fill them in.

Our questionnaire was composed of two validated scales-the self-reported Liebowitz Social Anxiety Scale for Children and Adolescents (LSAS-CA-SR) and the brief version of the WHO quality of life questionnaire (WHOQOL-BREF). We sought permission from the authors to allow us use of these questionnaires.
Data were entered into EpiData3.1 and exported into IBM Statistical Program for Social Sciences version 22 (SPSS 22). Data were screened and coded according to the instructions for each of LSAS-CA-SR and WHOQOL-BREF scales. We computed $\chi 2$-test to study the relationship between social anxiety and demographic variables, and independent samples t-test and Pearson productmoment correlation coefficient to study the relationship between social anxiety and quality of life. A p-value of less than 0.05 was considered significant.

Approximately $24 \%$ of the participants missed at least one question on the LSAS-CA-SR scale, making it difficult to calculate and categorize the final score. This was also true for WHOQOLBREF. To reduce the impact of a diminished sample size, we filled the missing data by imputation [16].

All of LSAS-CA-SR and WHOQOL-BREF variables were set for multiple imputations by AUTO method. Five imputed data sets were generated and used in analysis. Splitting the file according to imputation number generated pooled measures. SPSS 22 does not give standard deviations for pooled estimates so standard deviations were calculated using the mean of standard deviations of all imputed data sets.

We shared our results with the principals of all four schools and provided a presentation to the schools to educate the children about social anxiety. We also gave recommendations to the schools such as putting in place of a buddy system and teacher mentorship program, and offered to assist them in these endeavors.

\section{Results}

We recruited 450 participants; the socio-demographic profile of the participants can be seen in Table 1 . With a cut-off value of $60,23.8 \%$ screened positive for social anxiety. The descriptive statistics for the LSAS-CA-SR and WHOQOL-BREF are summarized in Tables 2 and 3, respectively. A chi-square test showed a significant difference in social anxiety between those who went to public compared to private schools (Table 4). Independent samples t-test revealed a statistically significant difference in the mean scores of children with and without social anxiety for all four WHOQOL-BREF domains (Tables $\mathbf{5}$ and 6). These results suggest that social anxiety does have an effect on quality of life.

Table 1 Socio-demographic profile of the participants.

\begin{tabular}{|c|c|}
\hline Demographic & Frequency \\
\hline \multicolumn{2}{|l|}{ Gender } \\
\hline Boys & 237 (52.7\%) \\
\hline Girls & 211 (46.9\%) \\
\hline Missing & $2(0.4 \%)$ \\
\hline \multicolumn{2}{|l|}{ Age } \\
\hline 14 & $3(0.7 \%)$ \\
\hline 15 & $43(9.6 \%)$ \\
\hline 16 & 184 (40.9\%) \\
\hline 17 & 220 (48.9\%) \\
\hline \multicolumn{2}{|l|}{ School Type } \\
\hline Public & 217 (48.2\%) \\
\hline Private & 233 (51.8\%) \\
\hline
\end{tabular}


Table 2 Descriptive statistics - minimum, maximum, mean, and standard deviation of scores for the LSAS-CA-SR scale.

\begin{tabular}{|c|c|c|c|c|c|c|}
\hline \begin{tabular}{|c|c|c|c|}
\hline Imputation Number \\
Pooled Data
\end{tabular} & N & Minimum & Maximum & Mean & Standard Deviation \\
\hline Fear & 450 & 0 & 55.4 & 19.3 & 11.7 \\
\hline Avoidance & 450 & 0 & 64.8 & 24.9 & 12.2 \\
\hline Total LSAS-CA score & 450 & 0 & 106 & 44.2 & 21.9 \\
\hline Valid N & 450 & & & \\
\hline
\end{tabular}

Table 3 Descriptive statistics for WHOQOL-BREF domains.

\begin{tabular}{|c|c|c|c|c|c|c|}
\hline Variable & N & Minimum & Maximum & Mean & Standard Deviation \\
\hline & & Pooled Data & & 52.9 & 12.1 \\
\hline Domain 1: Physical & 450 & 13.0 & 81.0 & 94.0 & 61.9 & 13.8 \\
\hline Domain 2: Psychological & 450 & 6.4 & 100.0 & 69.1 & 21.1 \\
\hline Domain 3: Social & 450 & 0.0 & 100.0 & 66.9 & 16.4 \\
\hline Domain 4: Environment & 450 & 0.0 & & \\
\hline
\end{tabular}

Table 4 Relationship between demographics and social anxiety status.

\begin{tabular}{|c|c|c|c|c|c|}
\hline & Social anxiety likely & Social anxiety unlikely & Total (100\%) & $\chi^{2}$-test (df) & $p$-value \\
\hline \multicolumn{6}{|l|}{ Pooled data } \\
\hline \multicolumn{6}{|l|}{ Gender } \\
\hline Male & $52(21.9 \%)$ & $185(78.1 \%)$ & 237 & \multirow{2}{*}{$3.260(1)$} & \multirow{2}{*}{0.071} \\
\hline Female & $61.6(29.2 \%)$ & $149.4(70.8 \%)$ & 211 & & \\
\hline \multicolumn{6}{|l|}{ Age } \\
\hline $14-15$ & $11(23.9 \%)$ & $35(76.1 \%)$ & 46 & \multirow{3}{*}{$1.5852(2)$} & \multirow{3}{*}{0.463} \\
\hline 16 & $41.4(40.5 \%)$ & $142.6(59.5 \%)$ & 184 & & \\
\hline 17 & $61.2(27.8 \%)$ & $158.8(72.2 \%)$ & 220 & & \\
\hline \multicolumn{6}{|l|}{ School type } \\
\hline Public & $71(32.7 \%)$ & $146(67.3 \%)$ & 217 & \multirow{2}{*}{$12.434(1)$} & \multirow{2}{*}{0.001} \\
\hline Private & $42.6(18.2 \%)$ & $190.4(81.7 \%)$ & 233 & & \\
\hline
\end{tabular}

Table 5 t-test comparing WHOQOL-BREF domains and mean Social anxiety scores for children with and without Social anxiety.

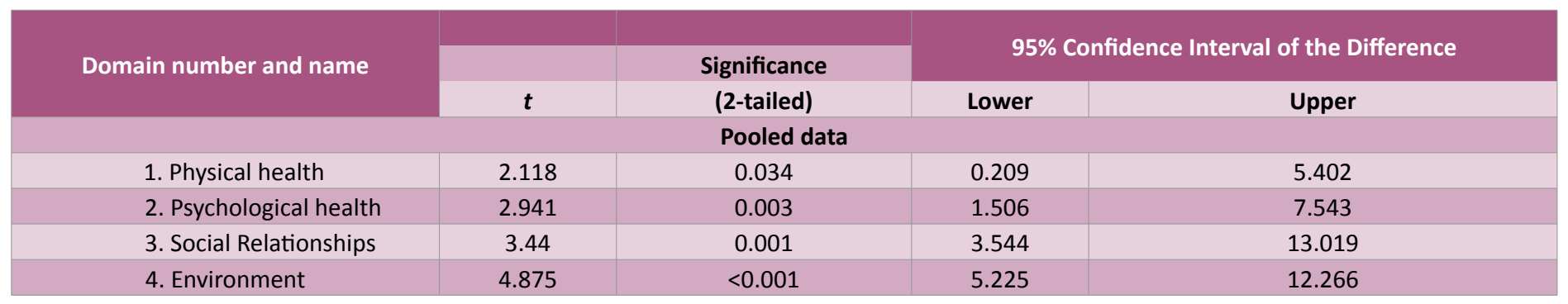

Table 6 Pearson product-moment correlation coefficients for WHOQOLBREF domain scores vs. LSAS-CA-SR scores.

\begin{tabular}{|c|c|c|}
\hline Imputation Number & $\begin{array}{c}\text { Pearson correlation } \\
\text { coefficient }(r)\end{array}$ & $p$-value \\
\hline Pooled Data & -0.129 & 0.006 \\
\hline Domain 1: Physical & -0.240 & $<0.001$ \\
\hline Domain 2: Psychological & -0.179 & $<0.001$ \\
\hline Domain 3: Social & -0.282 & $<0.001$ \\
\hline
\end{tabular}

\section{Discussion}

In our sample, $24 \%$ screened positive for social anxiety. This result is comparable to that of Al Khathami, who in a sample of 564 Saudi Arabian students found a prevalence of 34\%, higher than that reported in Western populations [8]. Social anxiety has a peak onset in teenage suggesting that during this time, genetic, behavioral, and environmental factors act synergistically in the pathogenesis of the disorder [17]. The United Nations terms adolescence the 'precarious decade,' a time when children undergo a host of physiological and psychological changes that herald the onset of puberty [5].

There was a preponderance of social anxiety in public school students as compared to their private-school counterparts. This could be because public school students belong to a lower socioeconomic status, a factor, which has been found to be associated with social anxiety $[18,19]$. Additionally, in government-run public schools there are limited opportunities for one-on-one mentorship as here not only is the student-to-teacher ratio is 
higher, they also report high rates of teacher absenteeism, placing their students at a disadvantage as mentorship from an adult or an older student is beneficial in lowering anxiety levels $[20,21]$.

Surprisingly, we did not find any disparity in Social anxiety rates among girls and boys. We expected that more girls would report social anxiety symptoms, because studies from the West indicate that girls are more likely to feel socially-anxious than boys as girls tend to be more conscious about their appearance and behavior [22]. We suggest two possible reasons for our result. First, cultural variation may be responsible as studies conducted in other Eastern countries such as China [18] and Saudi Arabia [8] too did not demonstrate any sex difference in Social anxiety symptoms. Second, literature indicates that girls indulge in 'co-meditation'mulling over negative experiences with friends, and this ability to foster close, confiding relationships protects against anxiety [8]. However, we did not assess the impact of co-meditation and close relationships in this study.

The data obtained in this study indicate that social anxiety levels have a negative relationship with perceived quality of life. Our results lend credence to the observations of previous investigators who have found that socially-anxious people fare worse on quality of life measurements as compared to their non sociallyanxious peers [8,23-25]. As this was a cross-sectional study, we could not ascertain if social anxiety causes a reduction in quality of life or if a poor quality of life causes feelings of social anxiety. In most cases, social anxiety goes unrecognized because people do not seek help [26]. Essau et al. found that in a sample of 1035 German adolescents in the age group of 12 to 17 , nearly $50 \%$ had a social fear, yet only a few students sought professional help [27]. A chronic condition, social anxiety causes marked functional deterioration that persists into adulthood and can lead to suicidal tendencies [28]. This bodes unwell for the future, as in Pakistan mental health is hardly a national priority. The cavalier attitude toward mental illness is evident by the fact that attempted suicide is a criminal offence in Pakistan, punishable by prison [29]. Against this background, the role of school personnel has become crucial in identifying and treating anxious adolescents. Schools are an efficient and inexpensive way of reaching out to a large body of adolescents. One study found that schools provide up to $70-80 \%$ of mental health services for students [30].

Our study used self-reported scales for studying social anxiety disorder in adolescents as this methodology reduces socialdesirability bias [31]. The study was conducted in the school setting as that is where children encounter many social scenarios (talking to unfamiliar classmates, asking questions in class, eating in public) that make them uncomfortable [26]. We recruited children because self-reports are recommended for studying social anxiety as they are deemed more reliable than reports from parents or teachers [8].

This study, however, did not include a diagnostic interview; the LSAS-CA-SR is a self-reported scale that can be used only as a screening tool or for monitoring response to treatment. The schools and study participants were selected by convenience sampling. We also could not include adolescents who had no access to schooling. Nationally representative surveys need to be conducted to gauge the burden of mental illness among children.

\section{Conclusion}

Our results suggest that social anxiety is prevalent among adolescents and socially-anxious adolescents endorse a lower quality of life. In view of our findings, we suggest that parents and teachers be educated about social anxiety and encouraged to collaborate in curtailing the spread of anxiety and mental illness in children. Efforts can be made to put in place a mentorship program where teachers or older students befriend and support younger students. Lastly, Ryan et al. have recommended a schoolbased group treatment program where students receive social skills training and exposure therapy to overcome their fears of social embarrassment [26]. Such programs are the need of the hour as they help adolescents cope with anxiety and stress.

\section{Acknowledgements}

We wish to thank Mrs. Quratulain Khairani of the Department of Community Health Sciences for all her support during the course of this project, Dr. Sarah Saleem and Mr. Iqbal Azam for reviewing the statistical analysis for the paper, and the schools and children who made data collection possible. 


\section{References}

1 Kashdan T, Herbert J (2001) Social Anxiety Disorder in Childhood and Adolescence: Current Status and Future Directions. Clin Child Family Psychol Rev 4: 37-61.

2 Diagnostic and Statistical Manual of Mental Disorders (2013) 5th ed: American Psychiatric Association.

3 Kessler R, McGonagle KA, Zhao S, Nelson C, Hughes, M, et al. (1994) Lifetime and 12-month prevalence of DSM-III-R psychiatric disorders in the United States. Results from the National Comorbidity Survey. Arch Gen Psychiatry 5: 8-19.

4 Jefferson J (2001) Social Anxiety Disorder: More Than Just a Little Shyness. Prim Care Companion J Clin Psychiatry 3: 4-9.

5 Brazier C, Ascencios M, Di Noia M, Gebre-Egziabher H, Grojec A, et al. (2011) The State of the World's Children-Adolescence: An Age of Opportunity. New York: UNICEF.

6 Burstein M, He J, Kattan G, Albano A, Avenevoli S, et al. (2011) Social phobia and subtypes in the national comorbidity survey-adolescent supplement: prevalence, correlates, and comorbidity. J Am Acad Child Adolesc Psychiatry 50: 870-880.

7 Chhabra V, Bhatia M, Sahil G, Kumar P, Srivastava S (2009) Prevalence of Social Phobia in school-going adolescents in an urban area. Delhi Psychiatry J 12: 18-25.

8 Alkhathami S (2015) Social Anxiety And Quality Of Life In Adolescents: Cognitive Aspect, Social Interaction And Cultural Tendency. Luton, England: University of Bedfordshire.

9 Hudson J, Rapee R (2000) The origins of social phobia. Behavior Modification 24: 102-129.

10 Population, Labour Force, and Employment (2015) Pakistan Economic Survey 2014-15, pp: 199-211.

11 Dryman M, Gardner S, Weeks J, Heimberg R (2015) Social anxiety disorder and quality of life: How fears of negative and positive evaluation relate to specific domains of life satisfaction. J Anxiety Disord 38: 1-8.

12 Katzelnick D, Kobak K, DeLeire T, Henk H, Greist J, et al. (2001) Impact of generalized social anxiety disorder in managed care. Am J Psychiatry 158: 1999-2007.

13 Jawaid A, Rehman T (2007) Paediatric Mental Health in Pakistan: A Neglected Avenue. Pak J Med Sci 57: 50-51.

14 WHO-AIMS: Mental Health System in Pakistan (2009) Islamabad: WHO Regional Office for EMRO, Cairo and Egypt WHO Headquarters.

15 Schneier F, Johnson J, Hornig C, Liebowitz M, Weissman M (1992)
Social phobia. Comorbidity and morbidity in an epidemiologic sample. Arch Gen Psychiatry 49:282-288.

16 Lin T (2006) Missing data imputation in quality-of-life assessment: imputation for WHOQOL-BREF. Pharmacoeconomics 24: 917-925.

17 Brook C, Schmidt L (2008) Social anxiety disorder: a review of environmental risk factors. Neuropsychiatr Dis Treat 4: 123-143.

18 Peng Z, Lam L, Jin J (2011) Factors associated with social interaction anxiety among Chinese adolescents. East Asian Arch Psychiatry 21: 135-141.

19 Hidalgo R, Barnett S, Davidson J (2001) Social anxiety disorder in review: two decades of progress. Int $J$ Neuropsychopharmacol 4: 279-298.

20 Demir S, Demir SG, Bulut H, Hisar F (2014) Effect of Mentoring Program on Ways of Coping with Stress and Locus of Control for Nursing Students. Asian Nurs Res 8: 254-260.

21 Pakistan Education Statistics. Islamabad, Pakistan, 2011-2012.

22 La Greca A, Lopez N (1998) Social anxiety among adolescents: linkages with peer relations and friendships. J Abnorm Child Psychol 26: 83-94.

23 Gultekin B, Dereboy I (2011) The prevalence of social phobia, and its impact on quality of life, academic achievement, and identity formation in university students. Turk Psikiyatri Derg.

24 Mendlowicz M, Stein M (2000) Quality of Life in Individuals With Anxiety Disorders. Am J Psychiatry 157: 669-682.

25 Wittchen H, Fuetsch M, Sonntag H, Muller N, Liebowitz M (2000) Disability and quality of life in pure and comorbid social phobia. Findings from a controlled study. Eur Psychiatry 15: 46-58.

26 Ryan J, Warner C (2012) Treating Adolescents with Social Anxiety Disorder in Schools. Child Adolesc Psychiatr Clin N Am 21: 105-109.

27 Essau C, Conradt J, Petermann F (1999) Frequency and comorbidity of social phobia and social fears in adolescents. Behav Res Ther 37: 831-843.

28 Colognori D, Esseling P, Stewart C, Reiss P, Lu F, et al. (2012) Selfdisclosure and mental health service use in socially anxious adolescents. School Mental Health 4: 219-230.

29 Khan M, Prince M (2003) Beyond Rates: The Tragedy of Suicide in Pakistan. Tropical Doctor 33: 67-69.

30 Burns B, Costello E, Angold A, Tweed D, Stangl D, et al. (1995) Children's Mental Health Service Use Across Service Sectors. Health Affairs 14: 147-159.

31 Nederhof A (1985) Methods of coping with social desirability bias: A review. Eur J Soc Psychol 15: 263-280. 